\title{
BREVE GENEALOGIA DE RELAÇÕES SAÚDE/DOENÇA NO DISCURSO MÉDICO: DUALISMO, MEDICINA CIENTÍFICA E DESAFIO BIOPOLÍTICO
}

\section{ARTIGO ORIGINAL}

SOUZA, Luiz Augusto de Paula ${ }^{1}$

COSTA, Rogério da ${ }^{2}$

MENDES, Vera Lúcia Ferreira ${ }^{3}$

SOUZA, Luiz Augusto de Paula. COSTA, Rogério da. MENDES, Vera Lúcia Ferreira. Breve genealogia de relações saúde/doença no discurso médico: dualismo, medicina científica e desafio biopolítico. Revista Científica Multidisciplinar Núcleo do Conhecimento. Ano 05, Ed. 06, Vol. 03, pp. 55-70. Junho de 2020. ISSN: 24480959, Link de acesso: https://www.nucleodoconhecimento.com.br/saude/discurso$\underline{\text { medico }}$

\section{RESUMO}

Este artigo efetua uma breve genealogia de concepções que, na tradição ocidental, levam à construção histórica e processual de ideias e conceitos sobre saúde e doença no discurso médico, até o momento presente, no qual a concepção usual faz com que as doenças correspondam a variações intrínsecas e específicas da saúde que, por

1 Doutorado em Psicologia. Mestrado em Fonoaudiologia. Graduação em Fonoaudiologia.

2 Doutorado em História da Filosofia; Mestrado em Filosofia; Especialização em História das Ciências; Especialização em Filosofia Leibniz e o Barroco; Especialização em Filosofia; Graduação em Engenharia de Sistemas e Computação.

${ }^{3}$ Doutora em Psicologia Clínica e professora doutora da Faculdade de Ciências Humanas e da Saúde da PUC-SP. 
sua vez, concerne à ideia de estado de bem estar biológico, psíquico, social e espiritual, que acaba por se estender também à noção mercadológica de vida saudável. As variações históricas e processuais nos modos de pensar a saúde e a doença, entre outros fatores, modificam a relação com os sentidos de temporalidade ou duração, finitude e modos de vida, e se expressam, atualmente, sob signos da biopolítica. Nesse sentido, o objetivo do estudo é o de, demarcando algumas das principais concepções médicas sobre o tema, fundamentar o desafio contemporâneo que enreda os processos de saúde/doença ao poder político, na condição de biopoder.

Palavras-chave: Saúde, doença, biopolítica.

\section{INTRODUÇÃO}

A história humana repõe ou reatualiza uma questão que lhe é fundamental, aquela que coloca o humano diante de si mesmo e, de certo modo, no avesso das coisas pelas quais se reconhece: estranhamento em face da dor, do sofrimento, da doença e da finitude. A busca de persistir na existência, modulada pelos significados a ela atribuídos no curso da história, que incluem a reflexão e as representações sobre a morte, constituem saberes e práticas destinados ao manejo dos fenômenos mórbidos.

A medicina, na condição de matriz da inteligibilidade e da reflexão sobre saúde e doença, como qualquer outra instituição ou saber, está ligada aos ideais e ideias de sua época; são certas percepções e representações sobre o homem, a natureza, a sociedade e suas forças econômicas, políticas, ideológicas e, mais recentemente, biopolíticas que lhe conferem sentido. As mudanças na medicina são definidas a partir de demandas sociais das quais faz parte ou às quais se adapta; e se assim ocorre não é por outra razão senão porque ela ocupa uma posição protagonista na cena institucional e no conjunto da organização da sociedade.

Essa constatação confronta, de saída, uma visão de senso-comum sobre a medicina, aquela em que lhe é atribuída uma espécie de vocação natural e uma coerência essencial, portanto intrínseca, caracterizando suas atividades sob um manto de 
"pureza" e "altruísmo", aparentemente desligadas dos interesses e disputas de poder, atualmente do biopoder, ou prática de soberania sob condições biopolíticas (HARDT e NEGRI, 2005), no interior das instituições do campo da saúde e das relações sociais.

Naturalmente, essa posição cede à história, à tradição ocidental da medicina e aos fatos. Muito esquematicamente: na antiguidade clássica, é possível dizer que a saúde é também considerada um dever dos cidadãos, fazendo dos cuidados médicos uma atividade que inclui os pacientes - por meio da contemplação e da aprendizagem sobre as doenças - na medida em que a cultura indica aos cidadãos e apenas a eles (mulheres, velhos, crianças, estrangeiros e escravos não são considerados cidadãos) o desenvolvimento das chamadas "técnicas de si mesmo", que representariam a elaboração das formas individuais de viver, no intuito de desfrutar ao máximo os prazeres materiais e espirituais da vida; na época medieval, o peso da influência eclesiástica fará com que a medicina do mundo cristão considere certos dogmas, como a sacralidade do corpo humano, o que ajudou a configurar aquilo que se convencionou chamar de uma medicina dos sintomas; finalmente, a partir da sociedade industrial e no âmbito da ciência moderna, a medicina desvendará, no interior e na espessura dos corpos, os dinamismos fisiológicos, fisiopatológicos e, mais recentemente, genéticos, passando a estar também no epicentro do desenvolvimento e da consolidação de um vasto setor tecnológico, industrial e de negócios na área da saúde, naturalmente sob forte influencia das regras de mercado e dos valores da sociedade de consumo.

A partir de tais contextos, este artigo seguirá caminhos que, sem a pretensão de exaustividade, levam dos sentidos clássicos das relações entre saúde e doença até o presente, em que há um deslocamento do conceito de saúde em direção à ideia de estado de bem estar, tanto biológico quanto psíquico, social e espiritual (AYRES, 2009), o que implicará também a noção mercadológica de vida saudável; aspectos e tendências que modificarão a relação com a temporalidade ou duração e com a finitude da vida sob signos da biopolítica. 


\section{A DOENÇA E A ORDEM SOCIOECONÔMICA: O DESEQUILÍBRIO DO CORPO}

Na Grécia Clássica, sob a rubrica hipocrática, verifica-se a busca obstinada da construção de uma "ordem" que pudesse, dominando a doença, regular a vida. Segundo Clavreul (1983), a "Patologia Humoral", constituída no período clássico, relacionava os elementos naturais (ar, terra, água e fogo) com os humores - líquidos corpóreos - (sangue, flegma, bílis amarela e bílis negra) e sobre eles fixava o estatuto da doença em oposição à saúde: se esta (eucrasia) é o equilíbrio entre aqueles componentes, a doença (discrasia) é o desequilíbrio, que deve ser reconduzido à situação da qual se desviou. Essa direção, indicada a partir do humanismo grego, influenciou e de certa forma ainda influencia uma série de concepções terapêuticas sendo, além de uma experiência histórica relevante, um dos alicerces do desenvolvimento do conhecimento médico:

cabe dizer mais sobre a Ordem Hipocrática, pois ela constituiu uma ordem jurídica no sentido de que fala Kelsen. O direito, diz Kelsen, não fala do ser (sein) mas somente do dever-ser (sollen) e os meios do direito (as sanções) estão destinados a fazer com que cada um aceda ao sollen. O homem tal como é definido pelo humanismo e pela medicina é da ordem do sollen. É o homem em boa saúde, aquele ao qual o homem poderá aceder se seguir as prescrições da razão e da ordem médica. 0 sein, o homem doente, não interessa à medicina (...) O médico não se dirige ao doente, mas ao futuro homem são, e se resta muito pouca saúde nele, ele tomará decisões em seu lugar, fará pressão sobre a família, eventualmente fará com que o internem.(...) O discurso médico não é um discurso sobre o homem, mas sobre a doença. Nem por isso deixa de implicar uma certa ideia implícita sobre o homem, sobre sua liberdade, sobre seu Ser. (CLAVREUL, 1983, p.74)

A medicina hipocrática pensa a saúde como uma espécie de dever do cidadão; a doença, por seu turno, corresponde a um inessencial que precisa ser debelado; o 
doente não é exatamente alguém, ele é algo como o suporte e o informante sobre a doença, sendo sua liberdade definida pela aceitação da ordem cujo médico é o representante.

Os parâmetros éticos e morais da medicina clássica estão fortemente ligados à lógica da organização social e sua prática reflete, claramente, essa indissociável ligação. Platão (1982) se refere à existência de dois tipos de medicina, uma para os homens livres e ricos e outra para os livres e pobres; os escravos não tinham acesso à assistência médica a não ser pelos cuidados de outros escravos ou dos chamados "práticos", que eram, geralmente, antigos escravos de médicos.

A medicina destinada aos ricos contemplaria, então, um sentido pedagógico, na orientação ao paciente e às pessoas que com ele convivessem, e uma espécie de sugestão psicológica realizada por meio de um "belo discurso", que deveria garantir a confiança do doente e a eficácia da terapêutica somadas, sobretudo, a uma individualização biográfica do tratamento. Tudo isso demandava tempo, paciência, conforto, riqueza e conhecimentos que permitissem a observação do mal pelo paciente e seus familiares.

O segundo tipo de medicina, para os pobres que, supostamente, não poderiam apreciar e nem se satisfazer com a observação do mal, era "resolutiva" e realizava, com alguma frequência, o envio dos doentes mais graves para locais segregados, sem outro recurso possível.

Período marcado pela grande incidência de epidemias, como peste, tifo, cólera, gripes, que recobrem toda a Europa, a idade média deixará um rastro de milhões de mortos, proporcionalmente maior entre os servos, mas bastante significativo também entre os senhores. Na perspectiva de Clavreul (1983), o período medieval é atravessado, desse ponto de vista, pelos signos da "peste" e da "morte", fazendo coincidir, de maneira bastante extrema, a ordem médica e a socioeconômica: para os pobres, a cristandade caritativa tomará a medicina pela via estreita da súplica, da oração e do diálogo com Deus, de resto, a liberdade dos enfermos será a aceitação da vontade divina que, ao menos em tese, tudo ordena e determina. Aos ricos, além 
do suposto alento religioso, será resguardado os cuidados de reconhecidos médicos da época.

O renascimento vai repor na ordem do dia ideais humanistas e naturalistas, substituindo, gradativamente, a transcendência medieval por uma concepção imanente, que plasmará o início da modernidade com o racionalismo moderno nascente. As mudanças que serão operadas na medicina, a partir daí, estarão impregnadas desses elementos que a prenunciam.

\section{A NOVA ORDEM DA DOENÇA: O CORPO GANHA PROFUNDIDADE}

No século XV, Paracelso golpeia a Patologia Humoral, concebendo a ideia de que a doença era um processo anormal do organismo, dando uma maior ênfase à sua composição química (quimiatria). Esse deslocamento terá como suporte outras ciências e a filosofia, na medida em que elas irão reservar um lugar de destaque à medicina, contribuindo em sua legitimação e firmando espaços para novas experiências médicas (CLAVREUL, 1983).

Descartes, defendendo as ciências naturais, por meio do primado empírico, dá o exemplo dessa medida:

efetivamente, essas noções fizeram-me enxergar a possibilidade de adquirir conhecimentos muito úteis para a vida e de encontrar, em substituição à filosofia especulativa que nas escolas se ensina, uma filosofia prática pela qual, conhecendo a força e a ação do fogo, da água, do ar, dos astros, do céu e de todos os outros corpos que nos rodeiam, tão distintamente quanto conhecemos os diferentes ofícios dos nossos artesãos, fosse-nos possível aplicá-los do mesmo modo a todos os usos a que se prestam, fazendo-nos como que senhores e possuidores da natureza. $E$ isso é tanto mais desejável(...), porém especialmente na manutenção da saúde, que é indubitavelmente o primeiro bem e o fundamento de todos os demais bens desta vida. Efetivamente, o espírito mesmo depende tanto das condições e da disposição dos órgãos do 
corpo que, se se conseguir encontrar o meio de tornar os homens mais prudentes, em geral, e mais hábeis do que o foram até aqui, creio que se deverá buscá-lo na medicina.(...) poderíamos nos livrar de uma infinidade de moléstias, seja do corpo seja do espírito e quiçá mesmo do enfraquecimento que a moléstia provoca, se possuíssemos conhecimento suficiente de suas causas e de todos os remédios que a natureza possibilita. (DESCARTES, 1975, pp. 77-78)

A medicina mantém-se sintonizada, claro, às ideias de sua época, sob um fundo histórico que traça seus contornos como um bem imprescindível ao homem, em cujo desenvolvimento acredita-se repousar parte significativa das respostas ou de suas possibilidades em relação à questões estruturais enfrentadas pela sociedade, e a problemas essenciais ao próprio conhecimento filosófico e científico. A medicina não só será instrumento importante na consecução dos objetivos do Estado moderno e do desenvolvimento do sistema de produção capitalista, como também será matriz para as ciências do homem (FOUCAULT, 1987).

O empirismo causal, que está na base da experiência moderna e é fundamento das ciências naturais, encontra-se presente, e não por acaso, nas bases da "Anatomia Patológica" lançadas por Morgagni em meados do século XVII, na qual é demonstrado que as doenças resultam de alterações materiais mais ou menos profundas nos órgãos. Estudo realizado por meio de autópsias, já indicava a transformação mais profunda pela qual passaria a medicina nos dois séculos que o sucederam.

Esse processo, iniciado na segunda metade do século XVII, no preâmbulo da medicina cientifica, terá seu ciclo completado apenas no século XIX, fazendo esse período compreender, como mencionado, mudanças sensíveis na medicina, que encontrará em sua dimensão clínica as condições necessárias à consolidação de seu caráter científico. Se durante a antiguidade clássica e a idade média a atividade clínica foi o campo de aplicação do saber médico, constituído alhures e relativo a um domínio coletivo das sociedades; a experiência moderna, segundo Foucault (op. cit.), transformará a clínica no lócus, por excelência, da investigação científica, integrando 
tratamento e pesquisa num mesmo movimento, que vai corporificar a medicina contemporânea.

De um lado, o desenvolvimento do capitalismo mercantil (acumulação primitiva) e depois industrial, somados ao advento da revolução burguesa, colocam em cena um contexto novo, cheio de novas demandas e desafios que, por outro lado, vão se refletir no intenso desenvolvimento da ciência. Do ponto de vista do conhecimento médico, esse período assinala duas mudanças importantes: em primeiro lugar a passagem da medicina das espécies para o estágio inicial da medicina clínica e, posteriormente, o advento da medicina dos tecidos (CANGUILHEM, 1982).

Ainda na perspectiva de Canguilhem, a medicina das espécies, influenciada por estudos e classificações botânicas, especialmente de Lineu, realizava uma classificação das espécies patológicas e desenvolvia uma prática ainda fortemente ligada às heranças hipocráticas e galênicas. Nela, as doenças eram tidas por entidades sem ligação necessária com o corpo, na medida em que sua ocorrência residia na mistura (por afinidade) de "qualidades" inerentes à doença ao temperamento dos pacientes, causando assim os desequilíbrios que definiriam as doenças. Daí também o julgamento de que as cidades, por seus ambientes pouco ou não naturais, seriam regiões mais propensas à incidência de enfermidades, e de que as epidemias não eram doenças como as outras, na medida em que, diferentemente das primeiras, não possuíam qualidades próprias e sim se configuravam como perturbações advindas de fatores externos, como a fome e o clima.

Nos primórdios da medicina clínica (século XVIII), em virtude do desenvolvimento de estudos físico-químicos aplicados à medicina, e das bases - já lançadas - da Anatomia Patológica, as doenças serão consideradas fenômenos dinâmicos, resultantes de um conjunto de sintomas que, misturados, definem as patologias e são, ao mesmo tempo, os sinais que permitem verificar sua ocorrência.

Essa mudança, todavia, não é suficiente para alterar mais radicalmente as bases sobre as quais a medicina se assentava, embora produza algumas das condições necessárias às transformações que estão em gestação ou, como disse Canguilhem 
(1982, p. 77), "apesar dos esforços dos iatromecanicistas e dos iatroquimistas, a medicina do século XVIII tinha permanecido, por influência dos animistas e vitalistas, uma medicina dualista, um maniqueísmo médico. A saúde e a doença disputavam o homem, assim como o bem e o mal disputavam o mundo."

\section{A MEDICINA DOS TECIDOS E O CORPO SOCIAL}

A segunda mudança referida, de maior profundidade e mais fundamental ao delineamento da medicina clínica moderna, refere-se ao surgimento, no limiar do século XIX, de um novo paradigma: a substituição da "medicina dos sintomas" pela "medicina dos tecidos", a teoria anátomo-clínica. As doenças já não denotavam espécies, nem conjuntos de sintomas mas, ao contrário, indicavam lesões em tecidos específicos.

Essa transformação foi fortemente influenciada pelo processo da revolução burguesa; nele vários fatores relacionados às atividades médicas chamavam atenção: o aumento dos enfermos em tempo de guerra, a carência de médicos, a degradação de seu ensino e sua inadequação em relação aos ideais e necessidades que a revolução evocava.

Defendendo a humanização dos cuidados de saúde, sua extensão como direito à população francesa e premidos pela intensa reivindicação popular, os poderes revolucionários, por muitas vezes, terão na ordem do dia as questões da assistência médica. A preocupação com a instituição de um modelo nacional de assistência terá, assim, um duplo caráter: tarefa de ordem prática e urgente mas, também, trabalho de fôlego político:

os anos anteriores e imediatamente posteriores à revolução viram nascer dois grandes mitos, cujos temas e polaridades são opostos; mito de uma profissão médica nacionalizada, organizada a maneira do clero e investida, em nível da saúde e do corpo, de poderes semelhantes ao que exercia sobre as almas; mito de um desaparecimento total da doença em uma sociedade sem distúrbios e sem paixões, restituída à 
sua saúde de origem. A contradição manifesta dos dois temas não deve iludir: tanto uma quanto a outra destas figuras oníricas expressam como que em preto e branco o mesmo projeto da experiência médica. Os dois sonhos são isomorfos: um, narrando de maneira positiva a medicalização rigorosa, militante e dogmática da sociedade, por uma conversão quase religiosa, e a implantação de um clero da terapêutica; o outro, relatando essa mesma medicalização, mas de modo triunfante e negativo, isto é, a volatilização da doença em um meio corrigido, organizado e incessantemente vigiado, em que, finalmente a própria medicina desapareceria com seu objeto e sua razão de ser. (FOUCAULT, 1987, p. 35)

Essa pretensiosa ilusão põe em marcha uma série de reformas que, balizadas por interesses políticos específicos, deveriam, por aproximações sucessivas, cumprir esses desígnios. As reformas pretendem tornar pública a medicina, impedindo que as desigualdades econômicas interfiram na à assistência de saúde; defendem e iniciam a generalização do tratamento domiciliar, reduzindo a assistência hospitalar aos casos em que os pacientes não possuíssem condições de serem tratados em casa; tentam reorganizar o ensino, buscando melhorar a precária formação existente e, ao mesmo tempo, diminuir o número de praticantes da medicina sem a devida qualificação e habilitação.

Vários planos foram discutidos, adotados, reformulados, descartados... Era intensa a movimentação e a mobilização em torno do problema. Porém, ainda segundo Foucault, as medidas iniciais não surtem os efeitos desejados: o número de escolas é incapaz de formar profissionais suficientes em relação à demanda; aumentam as querelas sobre a inadequação de um ensino que, isolado da prática, não dava conta de uma formação satisfatória aos seus estudantes; havia dificuldades efetivas em controlar e fiscalizar o exercício profissional. Fatores desse tipo somados aos "perigos" de contágio das doenças ou fatores correlatos vão reavivar a experiência dos hospitais, reorganizando todo seu campo de operações. 
Os hospitais não só poderão dar respostas mais massivas ao elevado número de enfermos, como serão o lugar da formação de seus profissionais, relacionando, assim, a assistência médica com a transmissão e constituição de seu conhecimento.

Definiu-se então um uso absolutamente novo do discurso científico: uso de fidelidade e obediência incondicional ao conteúdo colorido da experiência - Dizer o que se vê; mas uso também de fundação e constituição da experiência - fazer ver, dizendo o que se vê; foi, portanto, necessário situar a linguagem médica nesse nível aparentemente muito superficial, mas, para dizer a verdade, profundamente escondido, em que a fórmula de descrição é ao mesmo tempo gesto de desvelamento. E este desvelamento por sua vez implicava, como campo de origem e de manifestação da verdade, no espaço discursivo do cadáver: o interior desvelado.(...) o equilíbrio da experiência desejava que o olhar colocado sobre o indivíduo e a linguagem da descrição repousassem no fundo estável, visível e legível da morte. Esta estrutura em que se articulam o espaço a linguagem e a morte - o que se chama de método anátomoclínico - constitui a condição histórica de uma medicina que se dá e que recebemos como positiva.(...) foi quando a morte se integrou epistemologicamente à experiência médica que a doença pôde se desprender da contranatureza e tomar corpo no corpo vivo dos indivíduos. É, sem dúvida, decisivo para a nossa cultura que o primeiro discurso científico enunciado por ela sobre o indivíduo tenha tido que passar por este momento da morte. (FOUCAULT, 1987, pp. 226-227)

Para tratar os pacientes, a atenção do médico precisará estar, a partir de então, voltada à obtenção de conhecimentos sobre a patologia no paciente individualmente tratado; funda-se um olhar meticuloso, que se prende plenamente ao seu objeto: o corpo doente. A morte entendida como um processo vital transforma-se no guia da anatomia clínica, revelando, por meio da dissecção dos corpos, as verdades invisíveis até então procuradas pela ciência médica. 
A obra de Xavier Bichat (Anatomia Geral) é expressão emblemática desse novo código perceptivo da medicina. Seus estudos histológicos serão o ponto de partida dos estudos de François Broussais em demonstrar que o conhecimento da patologia baseia-se também na fisiologia e não somente na anatomia; explicando as febres como reações patológicas provocadas por lesões em tecidos. Fecha-se o círculo: a medicina clássica é substituída pela medicina científica, cujo objeto passa a ser o corpo doente, não mais a doença como fenômeno de natureza própria.

A medicina clínica estabelece, então, uma nova disposição fundamental do saber a partir da conversão do homem em objeto de conhecimento. Inflexão de peso, que não só inaugura um outro estatuto do humano em relação ao mundo e a si mesmo, como constitui instrumentos importantes para a condução e organização da sociedade ocidental em termos de regulamentação, regulação e controle da vida social:

daí o lugar determinante da medicina na arquitetura do conjunto das ciências humanas; mais do que qualquer outra, ela está próxima da disposição antropológica que as fundamenta. Daí também seu prestígio nas formas concretas de existência: a saúde substitui a salvação dizia Guardia. É que a medicina oferece ao homem moderno a face obstinada e tranquilizante de sua finitude; nela a morte é reafirmada, mas, ao mesmo tempo conjurada; e se ela anuncia, sem trégua, ao homem o limite que ele traz em si, fala-lhe também deste mundo técnico, que é a forma armada, positiva e plena de sua finitude. (FOUCAULT, 1987, p. 228)

Mundo técnico que não cessa de produzir novos "aparatos", como os que vão decorrer dos estudos genéticos, que desvendarão a patogenia de diversas doenças e a base constitucional de muitas manifestações e agravos de saúde. Conquistas científicas relevantes, sem dúvida, mas que são oferecidas, às vezes, sob a forma de apologia aos supostos homem e sociedade ideais: mitos revividos.

Ao encontro dessa onipotência cabe, ainda hoje, o alerta de Canguilhem (1982, p. 255): 
na reta de chegada desse sonho, encontra-se a polícia dos genes, encoberta pela ciência dos geneticistas. No entanto, não se deve deduzir daí a obrigação de adotar uma permissividade genética, mas apenas a obrigação de relembrar à consciência médica que sonhar com remédios absolutos é, muitas vezes, sonhar com remédios piores que o mal.

\section{BIOPOLÍTICA NO SÉCULO XXI: CONCEITO MIDIATIZADO DE SAÚDE}

As palavras de Canguilhem prenunciavam mudanças mais profundas, reservadas ao século XXI: os conceitos de saúde e de vida sofreriam inflexões decisivas na esteira da revolução dos estudos moleculares. No momento em que Foucault, Deleuze e Guattari promoviam a crítica do conceito de sujeito em favor da ideia de processos de subjetivação, já estava em curso, no final dos anos de 1970, uma verdadeira revolução no campo das biotecnologias e dos estudos genéticos.

Essa movimentação da ciência, até então subterrânea aos olhos do público, iria determinar toda uma nova forma de relacionamento da sociedade com o conceito de vida e de saúde, fato que se desdobra e se consolida ao longo dos anos de 1990. A tradução dessa emergência se deu, de maneira geral, com a propagação, nos meios midiáticos, das diversas inovações que a ciência estaria promovendo no campo da genética, dos transplantes, implantes, cirurgias, alimentação, transgênicos, etc. Essa transposição do discurso científico ao público leigo, isto é, a midiatização da saúde e da doença significou uma mudança considerável para uma enorme gama de hábitos e costumes das populações, bem como para o conceito de saúde que passou, gradativamente, a ser entendido no interior da esfera mais ampla do estado de bem estar e também de uma certa ideia de vida saudável.

Não há mais dúvidas sobre o papel que desempenham as ciências da vida na forma das biotecnologias atuais (ZORZANELLI e CRUZ, 2018). Exemplos são inúmeros, a começar pelo que se considera hoje uma vida saudável. As descobertas científicas sobre os mecanismos metabólicos do corpo humano têm apontado para uma série de hábitos considerados perniciosos à saúde. A presença de gordura, açúcar e sal - por 
exemplo - em alimentos tem sido foco de atenção especial entre especialistas. São associadas ao consumo em excesso desses componentes uma série de doenças ou de correlações com doenças. Portanto, todos esses estudos acabam por repercutir na vida cotidiana dos indivíduos, reorientando condutas e hábitos. Também fatores referentes à boa forma física tem sido objeto de estudos cada vez mais detalhados. Isso também tem redirecionado aspectos da vida cotidiana da maior parte da população. O consumo de tabaco e álcool são, evidentemente, combatidos por inúmeros estudos científicos, por revistas especializadas e campanhas midiáticas.

O que se quer apontar, aqui, não é tanto a evidência de que os hábitos estão mudando em função das descobertas científicas, mas sim de que essas descobertas estão promovendo todo um conjunto de políticas da vida, que podem e devem ser ditas biopolíticas, uma vez que elas se expressam pela articulação entre um campo de enunciados verídicos, justamente os enunciados com base na ciência, e se prolongam num conjunto de práticas de governamentalidade, de governo de condutas individuais, que são tanto as próprias condutas de cada indivíduo, quanto aquelas que cada indivíduo passa a exigir dos outros. Têm-se, com isso, o desenho de uma sociedade de controle extremamente sofisticada, bem distante das antigas disciplinas referidas por Michel Foucault em Vigiar e Punir. O governo de si implica hoje em um exercício cotidiano de ação sobre si mesmo, seja em relação aos alimentos consumidos, à prática de exercícios, à mudança de hábitos, seja em relação aos modos de se comportar diante do meio ambiente e, como consequência, em relação às atitudes de preservação e sustentabilidade tão difundidas atualmente. Mas o problema é que o governo de si acaba por se prolongar num governo do outro, numa espécie de planificação biopolítica que desenham o próprio "ser" dos indivíduos e da sociedade. Trata-se de uma forma de controle quase silenciosa, que opera no cotidiano de olhares, comentários e comportamentos, um regime de signos que cria e propaga determinada moral política ou, mais precisamente, biopolítica, uma vez que opera em função de controles sobre o corpo orgânico, tanto em relação às condutas e relações com o outro (riscos à saúde), quanto em termos de controles internos ao corpo biológico, por meio de drogas, intervenções estéticas, cirúrgicas, etc. 
Esse quadro, traçado assim sumariamente, já serve para introduzir o aspecto que mais interessa aqui: a biopolítica trouxe à cena o elemento que parecia oculto nas discussões sobre o sujeito e a subjetividade. Ela introduziu, justamente, o debate sobre a vida nela mesma, sobre o conceito de vida (FOUCAULT, 2004). Não apenas a vida biológica, mas os modos de vida que se apoiam, evidentemente, no biológico. A consideração do biológico se dá em função das formas de vida, e as condutas regulam as formas de vida, por meio de ações também no âmbito biológico. Por essa razão, Nikolas Rose, sociólogo inglês, afirma que a política da vida de nosso século é bem diferente daquela que Foucault descreve para o curso entre os séculos XVIII e $\mathrm{XX}$ :

ela não está delimitada nem pelos polos de doença e saúde, nem focalizada em eliminar patologias para proteger o destino da nação. Ao contrário, está preocupada com nossas crescentes capacidades de controlar, administrar, projetar, remodelar e modular as próprias capacidades vitais dos seres humanos enquanto criaturas viventes. (...) Trata-se de uma política da vida em si mesma. (ROSE, 2013, p. 16)

Com os avanços da biomedicina, das pesquisas com células-tronco, da engenharia genética, dos testes e sequencializações genéticas, das tecnologias de reprodução, dos transplantes de órgãos, da manipulação de órgãos in vitro... ativou-se um imaginário popular que recuperou fantasias alimentadas pelas ficções científicas do século XX, revivendo, mais uma vez, as ilusões modernas dos séculos XVIII e XIX sobre o homem e a sociedade ideais. Os seres humanos passaram a sonhar concretamente com uma vida sem dores, com um mundo onde fosse possível rejuvenescer ou permanecer belo por muitos anos, com a possibilidade de alterar seu estado emocional e mesmo sua inteligência por meio de psicofármacos e, no limite, de prolongar a própria vida de modo quase indefinido. Mas como os sonhos podem se tornar pesadelos, não houve quem deixasse de apontar os perigos dessa abertura à manipulação da vida que as técnicas da biomedicina passaram a viabilizar. Nikolas Rose afirma que 
tais perspectivas têm suscitado esperanças e temores, expectativas e medos, celebração e condenação. Enquanto alguns investem grande esperança nas perspectivas de curas novas e eficazes para todos os tipos de doenças e aflições, outros advertem para os perigos de tratar a vida humana como infinitamente maleável, especialmente onde estão implicados a criação e o uso de embriões humanos no tratamento da fertilidade ou na pesquisa. (ROSE, 2013, p. 14)

Para além das preocupações com a manipulação sem controle da própria vida, que tais técnicas podem acarretar, há muitas dúvidas sobre o papel do setor produtivo, representado aqui pelo complexo industrial da saúde, e os enormes interesses econômicos implicados na nova indústria da bioeconomia. Trata-se de um setor que nasce sob o signo da suspeita, por várias razões.

Há muitas chances de que a pesquisa básica se veja submetida a interesses econômicos de grupos poderosos de investidores e não se sabe ao certo como se lidará com os grupos de interesse, que representam indivíduos acometidos por males genéticos específicos e que desejam que as pesquisas possam avançar o mais rapidamente possível na direção da solução de suas doenças não de outras. No entanto, certamente isso não é o mais grave, dentre a miríade de agravos que afetam os seres humanos, há grande possibilidade de que apenas aqueles que oferecerem maior lucratividade e que representarem interesses geopolíticos específicos (guerras e outras disputas políticas e econômicas) tornarem-se objeto do desenvolvimento de substâncias, fármacos e outras tecnologias de intervenção sobre a vida. Essas suspeitas sugerem que as questões sobre a saúde e a doença estão sendo tomadas por práticas de soberania sob signos biopolíticos, ou seja, estão sendo tomadas pelo biopoder (Hardt e Negri, 2005), na condição de um poder avassalador sobre a vida e a morte.

Nesse sentido, Rose $(2013$, p. 15) faz a pergunta inquietante: "quem deveria ter o poder de tomar decisões em cada uma das situações perturbadoras em que se deve fazer uma escolha acerca da seleção de um embrião, da condução de um experimento, do licenciamento de um remédio, da cessação de uma vida?" 
Desenha-se uma política sobre a vida, que alimenta uma noção de saúde ligada à ideia de vida saudável que, fortemente midiatizada, aparece como um apelo óbvio e um valor incontestável. No entanto, nos termos em que é "vendida" pelo mercado da saúde, a vida saudável corresponde a uma condição pela qual se deve lutar cotidianamente para idealmente alcança-la. Há aqui uma espécie de deslocamento temporal, do presente ao futuro, na medida em que se promove o desejo de mudança de uma forma de vida presente em função de outra forma de vida a conquistar, cuja realização requer a passagem por ações na condição biológica de cada corpo; passagem que depende, não do uso, mas da submissão à lógica e às práticas da biotecnologia.

As expectativas dos indivíduos, criadas pelas novas biotecnologias e pelas pesquisas nas ciências da vida (mas não apenas por elas), apoiam-se na crença de que é possível usufruir de uma nova forma de vida ao se atuar nas condutas e hábitos que se atrelam ao biológico, intervindo de modo farmacológico, protético ou cirúrgico no próprio corpo, não apenas para tratar doenças, mas para moldar-se como sujeito. Esse tipo de relação com o futuro faz o presente variar constantemente para se adaptar à novas drogas, terapêuticas e condutas, que respondam à demandas biopolíticas de saúde, beleza, longevidade e felicidade. Seria isso, de fato, uma vida saudável?

\section{CONCLUSÃO}

A história da medicina, na condição de matriz de inteligibilidade dos cuidados à saúde, equivale em alguns de seus termos à própria história humana, em busca de compreensão e domínio da natureza e de si mesmo. A rápida genealogia aqui realizada sugere um problema - constituído historicamente - que ganha maior relevância nas configurações da vida e da saúde no contemporâneo e, por isso, talvez não deva ser negligenciado: o domínio sempre desejou ser pleno, mas no plano do biopoder opera, efetivamente, desde o interior dos corpos, da espessura orgânica da vida, em seus dinamismos físicos e psíquicos, numa espécie de movimento de totalização nunca antes experimentado. 
Num mundo assim, a promessa de uma "vida saudável" é de pouco mistério e talvez nenhuma dúvida, quem sabe uma vida mais longa, mas o preço a pagar é o da perda da potência para agir na alteridade, isto é, para agir sem a submissão aos controles sobre o corpo e a vida.

Esse cenário, gerador de enormes expectativas, ultrapassa em muito a simplicidade dos sonhos de saúde e de eterna juventude que o cidadão comum alimenta. Sua complexidade reside, sobretudo, na evidência de que a manipulação da vida coloca o indivíduo diante de questões que jamais havia enfrentado, e impõe uma interrogação ética e política relevante: que tipo de ser humano, de sociedade e de relação com o meio ambiente queremos ajudar a construir? Em 2020, sob o signo da maior pandemia dos últimos cem anos, ilusões de um mundo finalmente saneado e com doenças totalmente sob controle são dissipadas, a destruição ambiental começa a cobrar sua fatura mais intensamente (ou o coronavírus não é também um efeito dos desequilíbrios ambientais?) e a escalada do biopoder pode ganhar contornos de pesadelo. Se for assim, a construção de respostas à indagação sobre o mundo que se precisa construir torna-se também uma questão de sobrevivência.

\section{REFERÊNCIAS}

AYRES, José Ricardo de Carvalho Mesquita. Prevenção de agravos, promoção da saúde e redução de vulnerabilidade. In: Martins, M.A.; Carrilho, F.T.; Alves, V.A.F.; Castilho, E.A.; Cerri, G.G.; Wen, C.C. (eds). Clínica Médica, vol 1, Barueri: Manole , 2009.

CANGUILHEN, Georges - O Normal e o Patológico, 2a ed., Rio de Janeiro, Forense Universitária, 1982.

CLAVREUL, Jean - A Ordem Médica, São Paulo, Brasiliense, 1983.

DESCARTES, René - Discurso sobre o método, São Paulo, Hemus, 1975.

FOUCAULT, Michel - O Nascimento da Clínica, 3a ed. Rio de Janeiro: Forense Universitária, 1987. 
. Vigiar e punir, $7^{\mathrm{a}}$ ed. Petrópolis: Vozes, 1989.

. Naissance de la Biopolitique. Paris: Gallimard/Seuil, 2004.

PLATÃO - The dialogues of Plato. vol. 1 New York, Random House, 1982. (2 vol.)

ROSE, Nikolas. A Política da própria vida. São Paulo: Ed. Paulus, 2013.

ZORZANELLI, Rafaela Teixeira e CRUZ, Murilo Galvão Amancio Cruz. O conceito de medicalização em Michel Foucault na década de 1970. Interface (Botucatu) [online]. vol.22, n.66, pp.721-731. Epub May 21, 2018.

HARDT, Michael e NEGRI, Antonio. Multitude: war and democracy in the age of empire. Hamish Hamilton, 2005.

Enviado: Junho, 2020.

Aprovado: Junho, 2020. 